\title{
The Perception of Physicians on Gender-Specific Differences in the Diagnosis of COPD: Results from a Questionnaire-Based Survey
}

This article was published in the following Dove Press journal: International Journal of Chronic Obstructive Pulmonary Disease

Chantal Raherison-Semjen'

Karen Mezzi ${ }^{2}$

Konstantinos Kostikas (1D) ${ }^{2}$

Alexander J Mackay ${ }^{3}$

Dave Singh ${ }^{4}$

'Department of Respiratory Diseases, University of Bordeaux, Bordeaux, France; ${ }^{2}$ Global Medical Affairs Department, Novartis Pharma AG, Basel, Switzerland; ${ }^{3}$ Airways Disease Section, National Heart and Lung Institute, Imperial College London, London, UK; ${ }^{4}$ Medicines Evaluation Unit, University of Manchester, Manchester University NHS Foundations Trust, Manchester, UK
Correspondence: Chantal RaherisonSemjen

Centre INSERM I 219 Equipe Epicene, BPH Bordeaux Population Health Research Center, Université de Bordeaux, ISPED Institut de Santé Publique d'épidémiologie et de Développement, I 46 Rue Leo Saignat, Bordeaux, 33076, France

Tel +33055757/234

Email chantal.raherison-semjen@ubordeaux.fr
Objective: To evaluate the perception of physicians on gender-specific differences in the diagnosis of chronic obstructive pulmonary disease (COPD) using a qualitative and anonymous questionnaire-based survey.

Methods: The survey was conducted amongst respiratory physicians attending a standalone educational conference (29-30 September 2017) using the SpotMe ${ }^{\circledR}$ App. The 20-item standardized closed questionnaire had pre-coded responses to questions on physician's profile, and perception of COPD diagnosis and existing comorbidities between genders. All the responses were recorded anonymously.

Results: Of 368 physicians who downloaded the SpotMe ${ }^{\mathbb{R}}$ App and had access to the survey, 132 (35.9\%) completed the survey. Respondents were predominantly hospitalbased (57.3\%), aged 30-49 years (54.2\%), male (56.5\%), and from large cities $(59.5 \%)$. $68.7 \%$ of physicians perceived the prevalence of COPD to be higher in men; over $50 \%$ of physicians perceived that women were more prone to the effects of smoking. More than $60 \%$ of physicians agreed that women experience more severe symptoms (anxiety and depression) and have reduced quality of life than men. Over $50 \%$ of physicians agreed that misdiagnosis/underdiagnosis of COPD in women was an important factor for genderdifferences.

Conclusion: Results from this survey indicate that the understanding of COPD burden in women varies among healthcare professionals.

Keywords: comorbidity, COPD, gender difference, physician perception, gender bias

\section{Plain Language Summary}

Chronic obstructive pulmonary disease (COPD) has traditionally been considered a disease more common in men than women, but recent evidence suggests an increased prevalence in women. An anonymous qualitative questionnaire-based survey among respiratory physicians was conducted (using a closed questionnaire with pre-coded responses) to understand their perceptions on gender-based differences in the diagnosis of COPD. Of the 132 physicians who completed the survey, more than $50 \%$ agreed that the incidence of COPD is rising in women and that they experience more severe symptoms and reduced quality of life than men. In addition, physicians perceived that smoking had a greater impact on women's health and is most often misdiagnosed or under-diagnosed than men, suggesting some awareness about gender-specific differences. Physicians also agreed that comorbid conditions including anxiety, depression and osteoporosis were higher among women than in men. There was no consensus on gender-specific differences in the risk factors for COPD and worsening of the disease. Overall, the results from the survey demonstrated a varied understanding of COPD 
burden in women among physicians, highlighting the need for further educational programmes to raise awareness and improve diagnosis in women with COPD.

\section{Introduction}

Chronic obstructive pulmonary disease (COPD) has traditionally been perceived as a disease of older men with a history of smoking. ${ }^{1}$ However, in recent years, prevalence and mortality of COPD has increased rapidly in women, with the number of deaths from COPD surpassing that of men in some countries. ${ }^{2}$ This increase in mortality rate is essentially due to an increase in the number of women who smoke worldwide. The 2020 Global Initiative for Chronic Obstructive Lung Disease (GOLD) report mentions that COPD prevalence is almost equal in men and women in developed countries. ${ }^{3}$ Research indicates that women are at a greater risk of smoke-induced lung function impairment, dyspnea, and poorer health status for the same level of tobacco exposure compared with men. ${ }^{4,5}$ In parallel with the increase in smoking among women, exposure of women to non-smoking-related COPD, such as burning biomass fuels, has also been observed in developing countries. ${ }^{6-8}$ The prevalence of non-smoking-related COPD has been observed to be higher among women versus men. ${ }^{9-16}$

Despite available evidence, COPD continues to be misdiagnosed or underdiagnosed in women. ${ }^{17}$ Women may also suffer a delay in diagnosis of COPD due to multiple factors including voluntary delay of access to a physician for consultation, delay in referral to a pulmonologist, or prevalence of symptoms of fatigue/depression that may point to a different type of treatment. This may result in major psychological distress and worse health-related quality of life $(\mathrm{QoL}) .{ }^{5,18}$ More women with COPD are likely to display anxiety and/or depression compared with men, with severe manifestations including phobia, panic attacks, and generalized anxiety. ${ }^{19}$ Thus, a better understanding of the difference in expression of COPD between men and women would facilitate optimizing treatment and improved patient care. In addition, there is also the need to raise awareness among respiratory physicians and patients of increased exacerbation risk in women compared with men and to monitor exacerbation risk when determining the appropriate course of treatment. ${ }^{20}$

The aim of this survey was to evaluate the perception of physicians on gender-specific differences in the diagnosis and prevalence of different comorbidities in COPD.

\section{Methods}

\section{Survey Description}

This was an anonymous qualitative questionnaire-based survey conducted using the SpotMe ${ }^{\circledR}$ App (SpotMe, Lausanne, Switzerland) by physicians who attended the Novartis BREATHING hybrid scientific conference held from 29-30 September 2017. The 20-item standardized, closed questionnaire had pre-coded responses to questions on physicians' demographics and perception of diagnosis of COPD and existing comorbidities between genders. The survey looked specifically at two questions:

1. Physicians' responses to gender differences in incidence, risk factors, symptoms and quality of life of patients with COPD.

2. Physicians' perception on the most important issues regarding gender-specific differences in women versus men with COPD.

\section{Statistical Analysis}

Descriptive statistics were used to present all data. Categorical variables were presented as count and percentages.

\section{Results}

\section{Physicians' Demographics}

A total of 368 physicians downloaded the SpotMe ${ }^{\circledR}$ App and accessed the survey; of whom, 132 (35.9\%) completed the survey. The majority of the physicians were men $(n=74$; $56.5 \%)$ aged $30-49$ years $(n=71 ; 54.2 \%) ; 75$ (57.3\%) physicians were working in hospital-based settings followed by private setting $(\mathrm{n}=35 ; 26.7 \%)$, academic $(\mathrm{n}=11 ; 8.4 \%)$, and primary care $(\mathrm{n}=10 ; 7.6 \%)$. The majority of physicians were from large cities $(\mathrm{n}=78 ; 59.5 \%)$ followed by small city $(\mathrm{n}=28 ; 21.4 \%)$, and rural locations $(\mathrm{n}=25 ; 19.1 \%)$.

\section{Physicians' Perception Differences on COPD Diagnosis}

The majority of physicians perceived that the prevalence of COPD is higher in men. More than $55 \%$ of physicians agreed that the incidence of COPD is rising in women versus men. Around $40 \%$ of physicians agreed that the risk factors for COPD were different in men and women; however, a similar proportion also disagreed on this question. About half of physicians felt that smoking has a greater impact on women's health compared with men. More than $60 \%$ of physicians agreed that women experience more severe symptoms and lower QoL; however, $\sim 20 \%$ were uncertain. 
Table I Physicians' Response to Gender Differences in Incidence, Risk Factors, Symptoms and Quality of Life in Patients with COPD

\begin{tabular}{|c|c|c|c|}
\hline \multirow{2}{*}{$\begin{array}{l}\text { Questionnaire } \\
\text { Based on Your Clinical } \\
\text { Experience, Do You Find } \\
\text { That }\end{array}$} & \multicolumn{3}{|c|}{ Physicians' Response ( $N=132)$} \\
\hline & $\begin{array}{c}\text { Yes } \\
\text { n (\%) }\end{array}$ & $\begin{array}{c}\text { No } \\
\text { n (\%) }\end{array}$ & $\begin{array}{c}\text { Uncertain } \\
\text { n (\%) }\end{array}$ \\
\hline $\begin{array}{l}\text { Prevalence of COPD is } \\
\text { greater in men than women* }\end{array}$ & $90(68.7)$ & $26(19.8)$ & $15(11.5)$ \\
\hline $\begin{array}{l}\text { There are more new females } \\
\text { with COPD than new males } \\
\text { with COPD* }\end{array}$ & $73(55.7)$ & $30(22.9)$ & $28(21.4)$ \\
\hline $\begin{array}{l}\text { The risk factors for COPD are } \\
\text { different in women versus men* }\end{array}$ & $56(42.7)$ & $57(43.5)$ & $18(13.7)$ \\
\hline $\begin{array}{l}\text { The effect of smoking has } \\
\text { a greater impact on women's } \\
\text { lung health than on men's }{ }^{\dagger}\end{array}$ & $70(53.8)$ & $33(25.4)$ & $27(20.8)$ \\
\hline $\begin{array}{l}\text { Women report more severe } \\
\text { symptoms for a given } \mathrm{FEV}_{\mathrm{I}} \\
\text { than men* }\end{array}$ & $82(62.6)$ & $22(16.8)$ & $27(20.6)$ \\
\hline $\begin{array}{l}\text { Women with COPD have } \\
\text { a reduced quality of life } \\
\text { compared to men with } \\
\text { COPD* }\end{array}$ & $86(65.6)$ & $20(15.3)$ & $25(19.1)$ \\
\hline $\begin{array}{l}\text { Women experience more } \\
\text { exacerbations of COPD than } \\
\operatorname{men}^{\dagger}\end{array}$ & $47(36.2)$ & $37(28.5)$ & $46(35.4)$ \\
\hline
\end{tabular}

Notes: *One physician did not respond; ${ }^{\dagger}$ two physicians did not respond. FEV forced expiratory volume in I second.

A similar proportion of physicians agreed, disagreed, or were uncertain regarding gender-specific difference in incidence of COPD exacerbations (Table 1).

\section{Physicians' Perception Differences on Gender Difference in Comorbidities}

Over $50 \%$ of physicians agreed that misdiagnosis or underdiagnosis of COPD in women is an important issue related to gender differences (Figure 1). The majority of physicians agreed that women were more susceptible to osteoporosis ( $80 \%$ versus $4.6 \%$ ), and that anxiety and/or depression was higher in women than in men ( $73.1 \%$ versus $9.2 \%)$.

Around half of physicians agreed that heart failure and hypertension were higher in men compared with women ( $49.2 \%$ versus $11.5 \%$ and $50 \%$ versus $16.2 \%$; Figure 2 ). Very few physicians $(5.4 \%)$ looked systematically for osteoporosis in all COPD patients; however, more than $50 \%$ would change COPD treatment based on existing osteoporosis (Figure 3).

\section{Discussion}

Globally, COPD has always been considered as a male predominant disease. There is evidence that the prevalence is increasing among women; however, the difference in prevalence rates between genders are not substantial, especially in the developed and high-income countries. Gender differences amongst COPD patients, with respect to prevalence, comorbidities, smoking, lung function deterioration, severity, exacerbation, clinical symptoms, and healthcare resource utilization have now been reported. ${ }^{21-25}$ In the current survey, physician perceptions reported gender-based differences in the diagnosis of COPD. More than half of physicians were aware of gender-specific differences in disease severity and health status, but were uncertain about gender differences in the

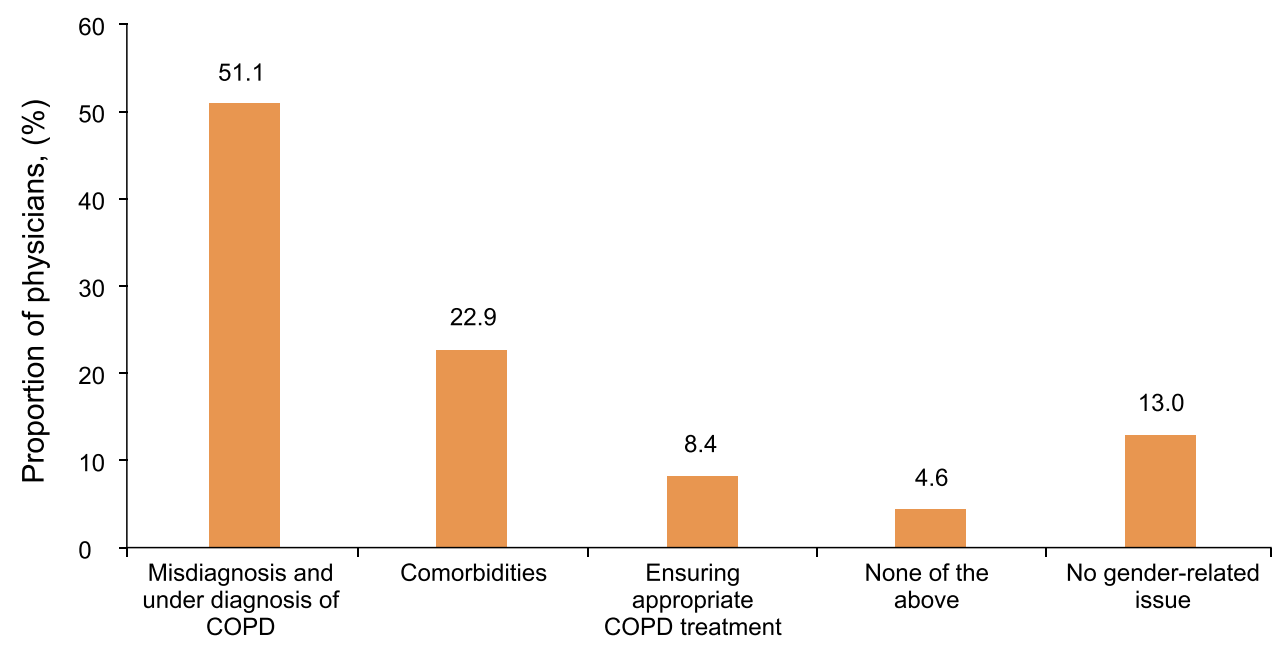

Figure I Physicians' perception on the most important issue leading to gender differences in COPD. 


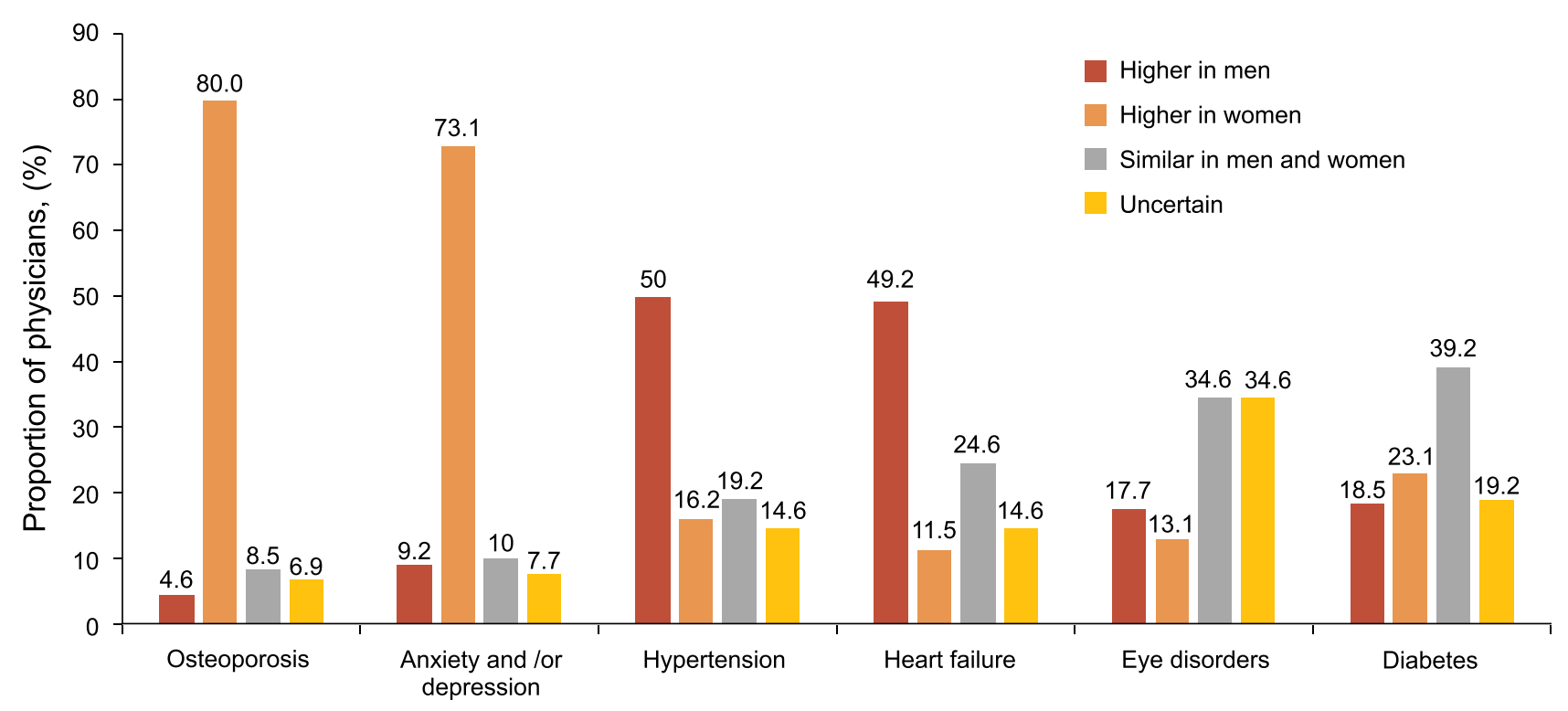

Figure 2 Physicians' perception on gender-specific differences in incidence of comorbidities in patients with COPD. Abbreviation: COPD, chronic obstructive pulmonary disease.

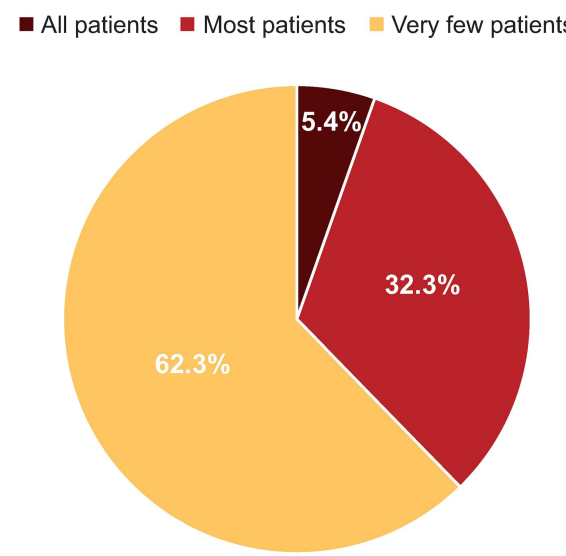

Physicians who look for osteoporosis in COPD patients
Women $\quad$ Men $\quad$ Both women and men $\quad$ Neither

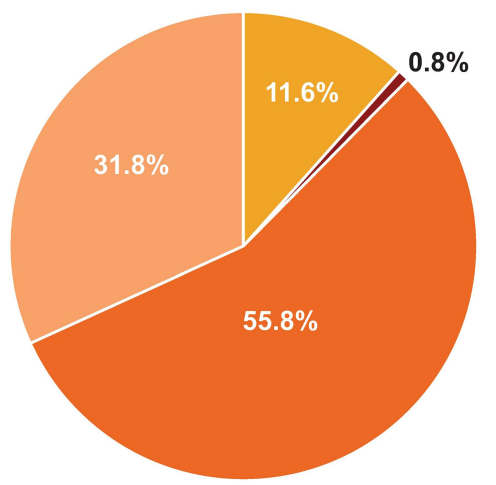

Physicians who would change the medication based on existing osteoporosis

Figure 3 Proportion of physicians who systematically examine for osteoporosis and would change the treatment approach based on existing osteoporosis in COPD patients.

Abbreviation: COPD, chronic obstructive pulmonary disease.

incidence of COPD exacerbations. However, over $40 \%$ of them did not recognize any gender-based differences in the diagnosis of COPD indicating a gap. Physicians agreed that comorbid conditions, including anxiety, depression, and osteoporosis, were higher among women compared with men, and would prefer to optimise the COPD treatment taking the existing comorbidities into account.

There exists a gender bias in the diagnosis of COPD, ie, there is a tendency towards diagnosing more men than women, making women largely underdiagnosed with $\mathrm{COPD},{ }^{17,21}$ mainly due to the underuse of spirometry; ${ }^{26}$
$51 \%$ of physicians in the current survey agreed that misdiagnosis or underdiagnosis in women is an important reason for gender-differences in COPD occurrence. In alignment with these survey findings, $73 \%$ of the patients with spirometric COPD criteria were found to be underdiagnosed, underdiagnoses being 1.27 times more frequent in women (86\%) than in men (67.6\%) $(P<0.05) .{ }^{17}$ It is also estimated that up to $13 \%$ of all patients diagnosed with COPD under the GOLD criteria are misdiagnosed. ${ }^{27}$ Furthermore, patients with heart failure, asthma, lung cancer, acute coronary syndrome, and ischemic heart disease 
have identical symptoms to those of COPD and hence may be misdiagnosed. ${ }^{28} \mathrm{~A}$ large proportion of men and women are shown to be misdiagnosed for asthma and COPD, especially in a primary care setting. ${ }^{29}$ This is not surprising considering that, regardless of the availability of consensus guideline diagnostic recommendations, confusion between COPD and asthma diagnosis remains common. ${ }^{30}$ The underdiagnoses and misdiagnosis of COPD is likely to have important implications in the care and treatment outcomes of patients.

COPD-related comorbidities are viewed differently in men and women. Cardiovascular disease is a frequent and important comorbidity in COPD, ${ }^{3}$ found to be more prevalent in men and general observations are consistent with the current survey findings where $49.2 \%$ of men had heart failure. Contrarily, previously published review articles showed that women with COPD present more frequently with heart failure, osteoporosis, and diabetes as compared with men. ${ }^{21,25,31}$ Also, women are more prone to develop osteoporosis and most likely at an early age versus men. ${ }^{2}$ Surprisingly, only of 5\% physicians systematically examined patients for osteoporosis and altered treatment approach based on existing osteoporosis. Regarding treatment, oral corticosteroids (CS) are a recognized risk factor at a cumulative prednisone equivalent dose $>7.5 \mathrm{mg}$ daily for $>3$ consecutive months, ${ }^{18}$ and high-dose inhaled CS are identified as being more detrimental in women. ${ }^{2}$ Thus, physicians should exercise caution while selecting COPD treatments so that the chosen therapy does not affect comorbidities in a negative manner. ${ }^{18}$ Furthermore, clinical evidence indicates that women with COPD are likely to report a higher degree of dyspnea, ${ }^{32}$ and are more likely to experience anxiety and depression. ${ }^{5,21,25}$ These findings were aligned with the current survey where $73.1 \%$ of women were perceived to suffer with anxiety and/or depression. Surprisingly, only $22 \%$ of physicians in the current survey considered comorbidity in women to be an important issue. Therefore, an informed decision needs to be taken for a personalized approach towards effective diagnosis of COPD in women.

While $36.2 \%$ of physicians in the current survey were of the opinion that women experience more exacerbations of COPD than men, in clinical practice, women were observed to be more prone to severe exacerbations, higher numbers of hospitalizations, and prolonged lengths of stay for hospitalizations as compared with men with COPD. ${ }^{20,33}$ Women were also shown to have a shorter time to first exacerbation and to being at a higher risk of exacerbation compared with men. ${ }^{4}$ Higher exacerbations in women have also been observed previously. ${ }^{21,24,25}$ It is postulated that the higher exacerbation rates in women could be due to differences in disease expression or the patterns of symptom reported. ${ }^{20}$ Contrarily, a systematic review in Latin America and the Caribbean showed that hospitalizations for COPD exacerbations are common in men. ${ }^{34}$

The current survey showed that over $50 \%$ of the physicians considered smoking to affect women's lung function more severely than men, and that $65.6 \%$ of the physicians agreed that women with COPD reported reduced QoL as compared with men. Similar to these findings, a cross-sectional, epidemiological study in central Sweden suggested that women with COPD with a heavy smoking history experience a poorer QoL than men with the same smoking intensity ${ }^{35}$ In a large COPD study in Norway, women were found to be associated with lung function reduction in subgroups of patients with early onset of COPD or low smoking exposure. ${ }^{23}$ The prevalence of non-smoking-related COPD was notably higher among women than men, ${ }^{9}$ especially the exposure to biomass- and indoor cooking-smoke. ${ }^{9,36,37}$ Thus, the majority of evidence has demonstrated that QoL deterioration is higher in women as compared with men. ${ }^{5,9,21,25,33,35,38}$ Likewise, it is important to note that the airways of women are relatively smaller for the same lung volume than men; this, combined with other biological, genetic and socio-cultural factors may be responsible for the observed gender differences in COPD. ${ }^{21,37}$ Moreover, there is a further need to investigate job-exposure-related COPD in clinical practice.

A limitation of using this questionnaire survey was that the findings could be biased due to differences in understanding of questions by the physicians. An additional selection bias could have been introduced in the study because this survey was conducted during a conference attended by a select group of physicians. Thus, there could be additional factors affecting COPD than those captured by the survey. However, the study offered meaningful insights into gender differences in the diagnosis of COPD.

\section{Conclusions}

The current survey findings showed that the understanding of COPD burden in women varies among respiratory physicians. They agreed that women are most likely to be misdiagnosed or underdiagnosed for COPD than men. Physicians' response to gender differences in incidence, 
prevalence, risk factors, symptoms, and QoL of women with COPD seems to be largely aligned with real-world clinical evidence. Further, educational programmes are required to raise awareness amongst physicians regarding increased COPD prevalence in women, and strategies to improve gender-specific diagnosis need to be identified.

\section{Abbreviations}

COPD, chronic obstructive pulmonary disease; CS, corticosteroids; GOLD, Global Initiative for Chronic Obstructive Lung Disease; QoL, quality of life.

\section{Data Sharing Statement}

Novartis is committed to sharing access to patient-level data and supporting documents from eligible studies with qualified external researchers. These requests are reviewed and approved by an independent review panel on the basis of scientific merit. All data provided are anonymized to respect the privacy of patients who have participated in the trial in line with applicable laws and regulations.

\section{Consent for Publication}

The current study did not involve recruitment of study subjects; hence exempted from institutional review board or ethics committee approval.

\section{Acknowledgments}

The authors thank Mohammed Najeeb Ashraf, B. Anupama, and Shaik AS (Novartis Healthcare Pvt. Ltd. India) for providing medical writing support/editorial support, which was funded by Novartis, in accordance with Good Publication Practice (GPP3) guidelines (http:// www.ismpp.org/gpp3). Dave Singh thanks the support received from the National Institute for Health Research (NIHR) Manchester Biomedical Research Centre (BRC), Manchester, United Kingdom.

\section{Author Contributions}

All authors contributed to data analysis, drafting or revising the article, have agreed on the journal to which the article will be submitted, gave final approval of the version to be published, and agree to be accountable for all aspects of the work.

\section{Funding}

The study was sponsored by Novartis Pharma AG, Basel, Switzerland.

\section{Disclosure}

Dr. Raherison-Semjen reports grants and personal fees from Astra Zeneca, personal fees from Chiesi, GSK, Novartis, outside the submitted work. K. Mezzi is an employee of Novartis; KK was an employee of Novartis Pharma AG at the time of the conduct of this analysis and has received honoraria for presentations and/or consulting services from AstraZeneca, Boehringer Ingelheim, Chiesi, ELPEN, GlaxoSmithKline, Menarini, Sanofi, NuvoAir, and Novartis, not related to this work. KK is also a member of the GOLD Assembly. AJM was a European Respiratory Society Fellow in Industry at Novartis Pharma $\mathrm{AG}$ at the time of conduct of this study and is currently employed and hold shares of AstraZeneca; Dr. Singh reports personal fees from AstraZeneca, personal fees from Boehringer Ingelheim, personal fees from Chiesi, personal fees from Cipla, personal fees from Genentech, personal fees from GlaxoSmithKline, personal fees from Glenmark, personal fees from Gossamerbio, personal fees from Menarini, personal fees from Mundipharma, personal fees from Novartis, personal fees from Peptinnovate, personal fees from Pfizer, personal fees from Pulmatrix, personal fees from Theravance, personal fees from Verona, outside the submitted work. The authors report no other conflicts of interest in this work.

\section{References}

1. Ntritsos G, Franek J, Belbasis L, et al. Gender-specific estimates of COPD prevalence: a systematic review and meta-analysis. Int J Chron Obstruct Pulmon Dis. 2018;13:1507-1514. doi:10.2147/COPD.S146390

2. Jenkins CR, Chapman KR, Donohue JF, Roche N, Tsiligianni I, Han MK. Improving the management of COPD in women. Chest. 2017;151(3):686-696.

3. Global Strategy for the diagnosis, management, and prevention of chronic obstructive pulmonary disease (2020 report); Global initiative for chronic obstructive lung disease. Available from: https://goldcopd. org/wp-content/uploads/2019/11/GOLD-2020-REPORT-ver1.0wms. pdf. Assessed June 1, 2020.

4. Celli B, Vestbo J, Jenkins CR, et al. Sex differences in mortality and clinical expressions of patients with chronic obstructive pulmonary disease. The TORCH experience. Am J Respir Crit Care Med. 2011;183(3):317-322.

5. Raherison C, Tillie-Leblond I, Prudhomme A, et al. Clinical characteristics and quality of life in women with COPD: an observational study. BMC Womens Health. 2014;14(1):31.

6. Raherison C, Girodet PO. Epidemiology of COPD. Eur Respir Rev. 2009;18(114):213-221.

7. Raherison C, Biron E, Nocent-Ejnaini C, Taillé C, Tillie-Leblond I, Prudhomme A. Existe-t-il des spécificités chez les femmes atteintes de BPCO? [Are there specific characteristics of COPD in women?] [Published correction appears in Rev Mal Respir. 2010 Dec; 27(10):1138]. Rev Mal Respir. 2010;27(6):611-624.

8. Liu S, Zhou Y, Wang X, et al. Biomass fuels are the probable risk factor for chronic obstructive pulmonary disease in rural South China. Thorax. 2007;62(10):889-897. 
9. Aryal S, Diaz-Guzman E, Mannino DM. Influence of sex on chronic obstructive pulmonary disease risk and treatment outcomes. Int J Chron Obstruct Pulmon Dis. 2014;9:1145-1154.

10. Hardie JA, Vollmer WM, Buist AS, Bakke P, Mørkve O. Respiratory symptoms and obstructive pulmonary disease in a population aged over 70 years. Respir Med. 2005;99(2):186-195.

11. Lamprecht B, Schirnhofer L, Kaiser B, Buist S, Studnicka M. Nonreversible airway obstruction in never smokers: results from the Austrian BOLD study. Respir Med. 2008;102(12):1833-1838.

12. Lindström M, Kotaniemi J, Jönsson E, Lundbäck B. Smoking, respiratory symptoms, and diseases: a comparative study between northern Sweden and northern Finland: report from the FinEsS study. Chest. 2001;119(3):852-861.

13. Zhou Y, Wang C, Yao W, et al. COPD in Chinese nonsmokers. Eur Respir J. 2009;33(3):509-518.

14. Ehrlich RI, White N, Norman R, et al. Predictors of chronic bronchitis in South African adults. Int J Tuberc Lung Dis. 2004;8 (3):369-376.

15. Kim DS, Kim YS, Jung KS. for Korean Academy of Tuberculosis and Respiratory Diseases. Prevalence of chronic obstructive pulmonary disease in Korea: a population-based spirometry survey. $\mathrm{Am}$ $J$ Respir Crit Care Med. 2005;172(7):842-847.

16. Cerveri I, Accordini S, Verlato G. For European Community Respiratory Health Survey (ECRHS) Study Group. Variations in the prevalence across countries of chronic bronchitis and smoking habits in young adults. Eur Respir J. 2001;18(1):85-92.

17. Ancochea J, Miravitlles M, García-Río F, et al. Underdiagnosis of chronic obstructive pulmonary disease in women: quantification of the problem, determinants and proposed actions. Arch Bronconeumol. 2013;49(6):223-229.

18. Gut-Gobert C, Cavaillès A, Dixmier A, et al. Women and COPD: do we need more evidence? Eur Respir Rev. 2019;28(151):180055.

19. Laurin C, Lavoie KL, Bacon SL, et al. Sex differences in the prevalence of psychiatric disorders and psychological distress in patients with COPD. Chest. 2007;132(1):148-155.

20. Stolz D, Kostikas K, Loefroth E, et al. Differences in COPD exacerbation risk between women and men: analysis from the UK clinical practice research Datalink data. Chest. 2019;156:674-684.

21. Aryal S, Diaz-Guzman E, Mannino DM. COPD and gender differences: an update. Transl Res. 2013;162:208-218.

22. Ntritsos G, Franek J, Belbasis L, et al. Gender-specific estimates of COPD prevalence: a systematic review and meta-analysis. Int J Chron Obstruct Pulmon Dis. 2018;13:1507-1514.

23. Sørheim I, Johannessen A, Gulsvik A, et al. Gender differences in COPD: are women more susceptible to smoking effects than men? Thorax. 2010;65:480-485.
24. Lisspers K, Larsson K, Janson C, et al. Gender differences among Swedish COPD patients: results from the ARCTIC, a real-world retrospective cohort study. Npj Prim. Care Respir. Med. 2019;(2019(29):45.

25. van Haren-willems J, Heijdra Y. Increasing evidence for gender differences in chronic obstructive pulmonary disease. Womens Health (Lond). 2010;6(4):595-600.

26. Chapman KR, Tashkin DP, Pye DJ. Gender bias in the diagnosis of COPD. Chest. 2001;119(2001):1691e1695.

27. Silva P. New COPD guidelines lead to misdiagnosis in certain patient subsets. Lung Disease News. 2015. Available from: https://lungdisea senews.com/2015/07/02/new-copd-guidelines-lead-misdiagnosiscertain-patient-subsets/. Accessed January 21, 2020.

28. Hangaard S, Helle T, Nielsen C, et al. Causes of misdiagnosis of chronic obstructive pulmonary disease: a systematic scoping review. Respir. Med. 2017;129:63-84.

29. Enrico H, Claudia C, Salvatore M, et al. Misdiagnosis of asthma and COPD and underuse of spirometry in primary care unselected patients. Respir. Med. 2018;142:48-52.

30. Tinkelman DG, Price DB, Nordyke RJ, Halbert RJ. Misdiagnosis of COPD and asthma in primary care patients 40 years of age and over. J Asthma. 2006;43(1):75-80.

31. Almagro P, López García F, Cabrera F, et al. Comorbidity and gender-related differences in patients hospitalized for COPD - The ECCO study. Respir Med. 2010;104:253-259.

32. de Torres JP, Casanova C, Hernandez C, Abreu J, Aguirre-Jaime A, Celli BR. Gender and COPD in patients attending a pulmonary clinic. Chest. 2005;128(4):2012-2016.

33. Hatice K, Nurdan K, Gulcin S, et al. Do females behave differently in COPD exacerbation? Int J COPD. 2015;10:823-830.

34. Ciapponi A, Alison L, Agustina M, Demián G, Silvana C, Edgardo S. The epidemiology and burden of COPD in Latin America and the Caribbean: systematic review and meta-analysis. J Chr Obstr Pulm Dis. 2014;11:339-350.

35. Hrisanfow E, Hägglund D. Impact of cough and urinary incontinence on quality of life in women and men with chronic obstructive pulmonary disease. J Clin Nurs. 2013;22:97-105.

36. Salvi SS, Barnes PJ. Chronic obstructive pulmonary disease in non-smokers. Lancet. 2009;374:733-743.

37. Han MK, Postma D, Mannino DM, et al. Gender and chronic obstructive pulmonary disease why it matters. Am $J$ Respir Crit Care Med. 2007;176(12):1179-1184.

38. Katsura H, Yamada K, Wakabayashi R, et al. Gender-associated differences in dyspnoea and health-related quality of life in patients with chronic obstructive pulmonary disease. Respirology. 2007; $12: 427-432$.

\section{Publish your work in this journal}

The International Journal of COPD is an international, peer-reviewed journal of therapeutics and pharmacology focusing on concise rapid reporting of clinical studies and reviews in COPD. Special focus is given to the pathophysiological processes underlying the disease, intervention programs, patient focused education, and self management protocols. This journal is indexed on PubMed Central, MedLine and CAS. The manuscript management system is completely online and includes a very quick and fair peer-review system, which is all easy to use. Visit http://www.dovepress.com/testimonials.php to read real quotes from published authors. 